\title{
QUANDO AS PERSONAGENS SE SENTAM À MESA: A NARRATIVA DE SENNA FERNANDES E LUÍS CARDOSO
}

\author{
WHEN CHARACTHERS SIT AT THE TABLE: \\ SENNA FERNANDES' AND LUIS CARDOSO'S NARRATIVE
}

\author{
Pedro d'Alte \\ Instituto Politécnico de Macau, Macau, China \\ pedrodalte@outlook.pt
}

Resumo: Senna Fernandes e Luís Cardoso são importantes escritores no panorama literário português e fornecem, sobre o Oriente, quadros literários que permitem, ao leitor, ampliar a experiência lusófona em vários prismas: social, étnico, histórico, cultural e literário. O presente exercício concretiza uma abordagem literária que torna mais visível a relação entre Macau e Timor. Sincronicamente, centrando-se nos momentos passados à mesa, a análise torna explícita choques identitários, conflitos étnicos e religiosos e determinados momentos históricos ocorridos entre as personagens, na primeira metade do séc. XX.

Palavras-chave: Literatura em português a Oriente; Senna Fernandes; Luís Cardoso

Abstract: Senna Fernandes and Luis Cardoso are important writers in the Portuguese literary panorama and provide literary pictures about the Orient that allow the reader to expand the Lusophone experience in various perspectives: social, ethnic, historical, cultural and literary. This exercise brings a literary approach that makes the relationship between Macau and Timor more visible. Synchronously, focusing on the moments spent at the table, the analysis makes explicit identity clashes, ethnic and religious conflicts and certain historical moments that occurred between the characters in the first half of the $20^{\text {th }}$ century.

Keywords: Portuguese Literature in Orient; Senna Fernandes; Luis Cardoso

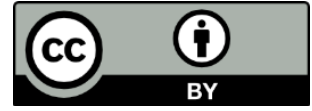




\section{1 À mesa com Senna Fernandes e Luís Cardoso}

Timor e Macau partilham a língua portuguesa num quadro de diglossia ou de poliglossia. Com efeito, por um lado, a língua portuguesa surge associada a contextos de uso oficiais, administrativos, religiosos, de ensino e, também, afetivos. Por outro, não se consubstancia como a língua mais disseminada, como o idioma que os falantes escolhem para interagir no seu quotidiano. No entanto, apesar de uma certa periferia quanto ao uso, é inegável que, a Oriente, existem interessantíssimas manifestações culturais em língua portuguesa. Para o presente exercício, confere-se destaque a dois importantes escritores lusófonos: Henrique de Senna Fernandes e Luís Cardoso.

Henrique de Senna Fernandes pertence a uma das mais antigas e ilustres famílias de luso-descendentes de Macau. Licencia-se em Direito pela Faculdade de Direito da Universidade de Coimbra, em Portugal. Regressado a Macau, exerce advocacia para garantir a sua independência financeira. Dedica-se também ao ensino, sendo professor e, posteriormente, diretor da Escola Comercial Pedro Nolasco - hoje, Escola Portuguesa de Macau - e, também, à escrita. Os mais afamados artefactos literários de Senna Fernandes são Nam Van. Contos de Macau, Amor e Dedinhos de pé, A trança feiticeira ${ }^{l}$ e Mong-Há - Contos de Macau. O macaense viria a falecer em 2010.

Luís Cardoso nasce no interior de Timor-Leste, em Cailaco. A sua vida académica inclui a passagem por colégios missionários: de Soibada, Fuiloro e o seminário de Dare. Quando se dá a revolução de 1974, Cardoso frequentava o Liceu Dr. Francisco Machado, hoje parte integrante do espaço físico da Universidade Nacional de Timor Lorosa'e. Já em Portugal, viria a formar-se em Silvicultura pelo Instituto Superior de Agronomia de Lisboa. São vários os títulos do literato timorense: Crónica de uma travessia - a época do ai-dik funam; Olhos de coruja, olhos de gato bravo; A última morte do coronel Santiago; Requiem para o navegador solitário; $O$ ano em que Pigafetta completou a circum-navegação; Para onde vão os gatos quando morrem.

Ambos os escritores são importantes figuras no panorama literário português e fornecem, sobre o quadro asiático, das mais pertinentes telas literárias, autênticas janelas escritas, ilustrativas das idiossincrasias da história, da experiência e da cultura autóctones.

O exercício concretizado no presente artigo intenta analisar passagens bastante específicas de uma obra de cada escritor: Requiem para o navegador solitário e Trança feiticeira. Enfocam-se, assim, determinadas peripécias: os momentos passados à mesa nas colónias portuguesas orientais nas décadas de 30 e de 40. Neste âmbito, os jantares assumemse, simultaneamente, como chave de leitura e como estruturador da análise.

A refeição partilhada é um momento crucial que força tanto a convivência como um determinado posicionamento físico, geralmente face-a-face. De certa forma, a dinâmica é mais rica do que o ensimesmado diálogo de espelho - perpetrado, por exemplo, pela figura de Narciso que fica condenado a um inferior patamar de eterna apreciação e de reflexão próprias. Com efeito, nas narrativas escolhidas, o jantar torna-se palco dinâmico de tensões políticas, etnoculturais e sociais que permitem desvendar retratos verosímeis dos homens e mulheres da época e, também, permitem ler as identidades abaladas de cada um, pois: identity only becomes

\footnotetext{
${ }^{1}$ Os títulos Trança feiticeira e Amor e Dedinhos de pé foram adaptados para cinema. O trailer do primeiro livro destacado pode ser encontrado no seguinte endereço: https://www.youtube.com/watch?v=ouRTm3Ev1rg. Acesso em 23 fev. 2020.
} 
an issue when it is in crisis, when something assumed to be fixed, coherent and stable is displaced by the experiences of doubt and uncertainty" (MERCER, 1990, p. 43).

De facto, estes recortes literários mostram imagótipos lusófonos bastante relevantes que logram colocar, em perspetiva, densos tópicos relacionados com a História, a cosmovisão dos povos, o status quo e as dinâmicas relacionais entre as várias figuras literárias. De certa forma, o narrador, ao evidenciar estes tópicos, adquire contornos etnográficos ${ }^{2}$ e contribui, de grosso modo, para o ideal assinalado por Venâncio, o de contextualizar os escritos e as experiências: "a obra de Henrique Senna Fernandes, assim como a de outros escritores macaenses [e timorenses] stricto sensu, será esteticamente mais valorizada se entendida como parte integrante da experiência literária lusófona" (VENÂNCIO, 2008, p. 691).

\section{Os preparativos}

\subsection{As personagens}

Catarina e Adozindo, ambos mestiços, no sentido em que são o resultado de processos de miscigenação, são as duas figuras literárias que aqui se colocam em evidência. Catarina é uma jovem indonésia cujo pai é chinês. Chega a Timor porque prometida a um capitão português, nascido em Goa, que geria os negócios do café em terras do sol nascente. Por seu turno, Adozindo é um belo macaense que se insere numa família de matriz cristã, patriarcal e de descendência portuguesa. ${ }^{3}$ Trabalha no escritório do pai, vive mimado pelas entidades femininas de sua casa e deambula entre a sedução de belas jovens e a fuga ao casamento com as mesmas. Conforme se percebe, a personagem de Catarina surge no romance Requiem para o navegador solitário 4 e o ser de papel Adozindo é o ator principal d'A trança feiticeira.

\subsection{O jantar}

Nada acontece de novo. Assim se inicia, e a negrito, o capítulo que traz a cena o jantar entre Catarina e o capitão do porto ${ }^{5}$ de Díli, capital de Timor. O jantar em apreço é promovido por Madalena, dama de companhia de Catarina que lhe vai sugerindo, num murmúrio três vezes repetido, o seguinte: "Porque não convidas o capitão do porto". A sugestão de Madalena intenta contrariar o spleen no qual a personagem de Catarina mergulha. A jovem "gata de jade" vive afundada num amor platónico que clama concretização. Envolve-a o afeto nebuloso por um

\footnotetext{
2 Trata-se de dar uma dimensão interpretativa à literatura tendo por base estudos históricos e antropológicos (CABRAL; LOURENÇO, 1993; FIRTH, 1989).

${ }^{3}$ A religião cristã é um pilar do pensamento e da atuação macaense da altura. O livro Making impressions. A portuguese family in Macau and Hong Kong, 1700-1945 é representativo de como a religião condiciona e modela o pensamento. Por exemplo, sobre o divórcio, o autor escreve: "The scylla of divorce in the conservatively Catholic Hong Kong Portuguese community was utterly unthinkable" (BRAGA, 2015, p. 312).

${ }^{4}$ A referência corresponde à edição de 2007, levada a lume pela editora Dom Quixote. Por sua vez, o título $A$ trança feiticeira corresponde à versão editada pelo Instituto Cultural do Governo da RAEM, em 2015. A estes correspondem e remetem as citações dos romances para os quais se usam as abreviaturas ' $R P N S$ ' e ' $T F$ ' respetivamente.

${ }^{5}$ Em vários momentos foram apresentados possíveis sentidos para o destaque conferido à frase inicial de cada capítulo (D’ALTE, 2014; 2019) e que podem estar relacionados com uma transposição cultural do elemento ‘odamatan' (porta) para o romance ou com a própria sedução que a frase bíblica "no início era o verbo" cria em Luís Cardoso.
} 
"navegador solitário" "6 que tarda em chegar e sobre o qual nada de palpável existe, salvo a cópia de um livro que a própria Catarina segura em mãos enquanto olha o horizonte plano e vazio.

Desiludida pelo conjuntura e pelas frustrações de amores passados, decide concretizar a sugestão de Madalena e convida, presencialmente e a viva voz, o capitão Geraldo Pinto Correia para um jantar a realizar na casa de Catarina.

O "belo Adozindo" é um jovem galã macaense. Apesar de moderadamente abastado, é, no entanto, a sua compleição e beleza físicas que fazem suspirar as suas pretendentes desde o largo de Camões até ao Cheok Chai Un $n^{7}$. O próprio sedutor é conhecedor da sua beleza: "Oh, Deus, obrigado por me fazeres tão bonito" (TF, p. 14). O jovem macaense, que se esgrima aos bons casamentos como um gato à àgua fria, acaba, após várias peripécias narrativas, por se enamorar por uma mera aguadeira ${ }^{8}$ do bairro chinês de Cheok Chai $U n^{9}$ - contrariando os planos de seu pai.

Depois de receber o convite de Catarina, o capitão surge à hora prevista, vestindo um traje de gala como se, de facto, a ocasião o requeresse. Madalena, quando da chegada do convidado, faz desaparecer da casa tanto as crianças como os gatos, permitindo a criação de um ambiente propenso a uma maior intimidade. O capitão do porto assume as rédeas da conversa e dá-lhe um cariz económico e político, recomendando à cicerone que reconsidere a sua posição. Ou seja, sugere que a jovem aceite a proposta dos japoneses e troque a cultura do café da sua fazenda pela do algodão, mais propícia aos nipónicos (RPNS, p. 88). O desenrolar da conversa torna evidente que tal escolha nada tem que ver com a propensão do solo timorense para gerar café ou algodão, mas antes com a necessidade de "escolher o lado certo" e aliar-se àqueles que serão os donos do mundo: Alemanha e Japão (idem, p. 89). Tal sugestão oculta uma traição simbólica, na medida em que o cultivo do café era rentável aos portugueses e às comunidades locais timorenses. ${ }^{10}$ A troca de uma cultura por outra insinua uma alternância no poder.

\footnotetext{
${ }^{6}$ O "navegador solitário" corresponde a Alain Gerbault. Sobre o navegador francês, Durand escreve: "Alain Gerbault ne paraissait pas vraiment destiné à devenir un aventurier solitaire des mers du Sud. Fils de bonne famille d'industriels alternant rallyes automobiles et tournois de tennis, il avait vécu un profond traumatisme lors de la Première Guerre mondiale. Enrôlé dans l'aviation naissante, il s'était fait remarquer pours ses grandes qualités de pilote" (DURAND, 2006, p. 308). A figura é proeminente e, sobre ela, existem algumas peripécias a relatar. O velejador torna-se um aventureiro que ruma até Oriente e que escreveria: "à Koepwang, capitale de Timor, l'île malaise, toute la fascination de l'Orient me séduit" (GERBAULT, 1991). Repare-se que Gerbault, no seu segundo regresso, opta por Díli e não Kupang - onde já estivera. Talvez buscasse a neutralidade de Lisboa face à guerra eminente. Quando aporta a Díli, em 1941, é co-protagonista de um episódio cómico. O navegador possuía um barco com o seu próprio nome. À chegada, o capitão do Porto ter-lhe-á dito: -Vem sozinho? É o novo Alain Gerbault (DURAND, 2006, p. 326; CARDOSO, 2007, p. 157). Vítima de doença, o navegador que andava em busca do sol, viria a falecer em Díli. Cinatti, localizaria a ossada do poeta e navegador francês e permitir-lhe-ia um funeral condigno.

${ }^{7}$ Se traduzido livremente, pode ler-se 'passarinho'. Opta-se pela grafia presente na obra A trança feiticeira (2015). 8 A profissão consiste em fornecer água potável às casas do bairro. A aguadeira em apreço deslocava-se nas imediações do bairro Cheok Chai Un onde existe o templo Fok Tak Chi, na rua Tomaz da Rosa. Neste templo, é de destacar a existência de um poço no qual, "noutros tempos, os residentes do bairro costumavam abastecer-se de água" (BARROS, 2003, p. 30).

${ }^{9}$ O bairro conhecido como "passarinho" situa-se nas traseiras do colégio Santa Rosa de Lima e nas imediações da base da entrada do Hospital Conde São Januário. O bairro de hoje pouco se assemelha ao relato concretizado por Senna Fernandes. No entanto, as referências topográficas, o templo, o mercado e um certo bairrismo característico continuam presentes no Cheok Chai Un dos dias de hoje.

${ }^{10}$ Ainda hoje, Timor produz um excecional café arábico e um importante café híbrido. De facto, na primeira metade do século XX, deu-se um fenómeno que conciliou a espécie arábica com a espécie robusta. Este tipo de café conseguia resistir à ferrugem. Este híbrido café de Timor-Leste teve difusão alargada a partir da década de 50 (GONÇALVES; RODRIGUES, 1976; SÁ, 1952).
} 
Na narrativa que apresenta Adozindo, o Japão possui poder semelhante: o de enegrecer o horizonte com o seu caráter bélico e imperialista. No entanto, neste texto, o tom é menos denso e sugere, de certa forma, alguma ignorância do povo macaense perante as intenções deste império. Em outros textos do panorama literário macaense, podem encontrar-se relatos mais abeirados e representativos do drama da guerra. Por exemplo, em Contos de Ou-Mun ${ }^{11}$, no qual se encontra as palavras de uma antiga pei pai-chai ${ }^{12}$ da afamada Rua da Felicidade:

\begin{abstract}
Ah! Sim, primeiro, foi o ópio e, por último, a tropa. Tudo acabou ou se mudou. Pelo meio, foi a voragem da guerra do Pacífico, com os japoneses a imporem serviços gratuitos e os refugiados e outros famintos a inundarem a baixa da cidade, passando a pente fino os caixotes do lixo, em busca de migalhas e detritos de sobrevivência, insuficientes para tantas bocas, que era vê-los definhar, membros sem forças, olhos vagueando na mais profunda tristeza, corpos enroscados no chão, à espera do sono que não tivesse despertar" (CORREIA, 1996, p. 64).
\end{abstract}

Apesar de n'A trança feiticeira a diegese ser mais omissa quanto às intenções bélicas do Japão, ainda assim, este país belisca o dia-a-dia macaense e prejudica, indiretamente, Adozindo quando este tenta obter emprego após cair na miséria: "empregos, agora que vinha uma crise com a guerra não declarada sino-nipónica? Nem pensar nisso, os empregos não estavam à mão de semear (TF, p. 118).

Claro está que a degradação da personagem de Adozindo e a necessidade de busca de emprego foram precipitadas pelo namoro com a aguadeira ${ }^{13}$ - mais assumido, com fulgor, após um jantar.

A refeição evocada insere-se num conjunto de situações curiosas. Contrariamente ao capitão do porto, Adozindo prescinde dos melhores fatos para ir ao encontro da aguadeira: "usara, de propósito, um fato velho e abandonara o rigor da apresentação" (TF, p. 59). Este aspeto torna evidente que o galã reconhece o hiato entre a sua condição social e a da chinesa. Também é revelador de uma tentativa de camuflar a sua presença num bairro pobre

\footnotetext{
${ }^{11}$ Pode traduzir-se por "boa porta" e designa Macau.

${ }^{12}$ Cortesãs da rua da Felicidade, em Macau. Tratam-se de mulheres, geralmente vendidas quando crianças, e que são ensinadas a entreter os homens. Por vezes, sabem dançar, poesia, desenho e xadrez. Senna, no seu livro Nam Van. Contos de Macau apresenta estas mulheres detalhadamente: "Nos tempos áureos do Bazar, não eram prostitutas vulgares. Não era de bom tom dormir com o freguês logo ao primeiro convite, porque isto era baratearse ignominiosamente. Só depois de muitas sessões e bem esportuladas é que concediam tal favor. Ninguém as podia obrigar a proceder contrariamente, porque a sua função era a de cantar. Aprendiam a gargantear, em falsete, longas canções de amor, lamentações de saudade e tristezas de separação. Ao mesmo tempo que dedilhavam o alaúde ou tangiam o piano de cordas com duas hastes finíssimas de bambu. O aprendizado porém, não se limitava, porém, a cantar e a conhecer as mais subtis práticas de amor. Ia mais longe e a cantadeira aprendia a ser essencialmente feminina e discreta de maneiras e a conversar. Ensinavam-lhe versos, pensamentos confucianos, lendas do país, expressões de gentileza e meneios de olhos e de mãos, tudo isto para entreter e seduzir. Possuía, em suma, uma requintada educação na arte de agradar. (...) As pei-pa-chais da Rua da Felicidade, geralmente compradas de pequeninas a pais miseráveis e paupérrimos, eram escolhidas a dedo. Se em muitas a beleza do rosto não coincidia com os padrões da estética ocidental, eram certamente bonitas para o gosto chinês (FERNANDES, 1997, p. 53-54).

${ }^{13}$ Apesar de rodeada por bastante água, a península de Macau padecia de graves problemas associados à falta de água potável. A população recorria, frequentemente, a água proveniente de fontes, poços particulares ou públicos e a cisternas construídas para aproveitar a água das chuvas. Uma das profissões associadas a tais dinâmicas, é o mister de aguadeira. O ofício consistia em transportar água de um poço até à casa do cliente. No blogue "Macau Antigo" existe um acervo que partilha fotografias da região. Numa delas se pode ver uma aguadeira a trabalhar: http://macauantigo.blogspot.com/2018/08/aguadeira-na-travessa-da-paixao.html [Acesso em: 20 fev. 2020]. Para mais informação sobre o tópico da água potável em Macau, pode ler-se o seguinte artigo: https://www.saneamentobasico.com.br/a-longa-luta-de-macau-pela-agua-potavel/ [Acesso em: 20 fev. 2020].
} 
e de reputação questionável para a elite. Recorde-se que Adozindo aproxima-se do ninho do amor à socapa e a intenção do galã era a de seduzir a moça, concretizar uma noite de amor e desaparecer. Este plano seria a paga pela vergonha que a jovem o fez passar no bairro, tendo-o enxotado a varapau perante uma plateia chinesa.

Ora, uma vez dentro de casa da aguadeira, o seu olhar externo de kuai-lou ${ }^{14}$ desvenda a habitação chinesa à luz da sua própria interpretação: "ali se comia, ali se dormia e ali se trabalhava. (...) Uma porta interior comunicava com outra divisória que devia servir de cozinha e também de cloaca para as necessidades" (TF, p. 60). Ver as condições de vida da pobre aguadeira materializou, em Adozindo, a consciência da diferença e a consequente comiseração: "Ao se defrontar com aquela crua pobreza, teve um rebate de consciência. Porque desinquietara aquela rapariga que não parecia revoltada e até se conformava com a sua situação?” (idem).

Curiosamente, a preparação do jantar permite ler uma verticalidade no movimento das personagens que denuncia o advir narrativo. ${ }^{15}$ Dito de outra forma, se Adozindo descende a um patamar inferior ao adentrar num bairro de má reputação e ao descuidar, propositadamente, a sua imagem imaculada com o intuito de materializar a paixão, A-Leng, a aguadeira, assume uma direção oposta. Leia-se: "tomara também banho, limpara-se da exsudação do mister, ajustara o cabelo, disciplinando os fios rebeldes e trocara de vestido, calças pretas de pano fino e um tun-sam ${ }^{16}$ de seda vermelha, com florinhas doiradas, as cores da felicidade (idem, p. 6061). Este investimento na criação de um momento inolvidável não se restringe à indumentária. A chinesa tinha trazido um chá que não seria barato e tinha preparado uma ceia.

Mais a sul, o jantar de Catarina vai adquirindo contornos disfóricos. Os temas de conversa descasam-se e acentuam as diferenças entre ambos. O capitão pretendia falar dos japoneses, Catarina não. Posteriormente, quando a Catarina interessou falar de Alain Gerbault, o capitão contrapôs Fernão de Magalhães, "Quem é esse Fernão de Magalhães? A pergunta fêlo olhar para mim como se eu fosse uma ignorante" (RPNS, p. 89).

Mais adiante, percebe-se que o capitão de porto, Geraldo Pinto Correia, não corresponde ao homem idealizado por Catarina. Não possui os traços de um aventureiro ou de um marinheiro prototípico. Não se mostra impulsivo ou apaixonado. Aliás, o seu futuro havia sido escolhido pelo pai. À mesa, mantém os traços da juventude e apresenta-se destituído de histórias excitantes ou sedutoras: "mesmo sentado, permanecia ereto como o mastro de um navio, uma estátua de pedra erigida num promontório a olhar para o infinito. Tinha ali o mar tão próximo e convidativo, podia dar um grande mergulho" (RPNS, p. 91). ${ }^{17}$

\footnotetext{
${ }^{14}$ Uma tradução ao pé da letra devolve a ideia de kuai ‘demónio' e lou 'homem'. Porém, o sentido é mais abrangente e designa o estrangeiro, aquele que tem práticas e costumes alheios. Leonel Barros fornece uma explicação mais abrangente: “Os chineses acreditam que as almas mal sepultadas transformam-se em espíritos maus, demónios, vampiros que vagueiam por toda a parte em grande número. A estas almas penadas que atormentam o mundo dos vivos é atribuída a expressão Kuai (diabos)" (BARROS, 2003, p. 75).

${ }^{15}$ No término da narrativa, é legítimo aferir que, socialmente, a personagem de Adozindo desceu do pedestal inicial no qual se encontrava. Por seu turno, a aguadeira registou uma ascensão social. Assim, pode dizer-se que se "encontraram a meio".

${ }^{16}$ Conjunto de camisa e calças do vestuário chinês (tradução proposta e presente no glossário do próprio livro). Sobre o traje da mulher em Macau, pode ler-se a obra de Ana Maria Amaro: O traje da mulher macaense. Da Saraça ao Dó das Nhonhonha de Macau.

${ }^{17}$ Ao ofício de marinheiro associa-se, invariavelmente, a presença de histórias de outros lugares inacessíveis senão pela palavra, pela evocação. No título Nam Van. Contos de Macau de Senna Fernandes, é evocado o arquétipo de marinheiro: "Pairou um silêncio entre nós e o oficial de bordo, figura ímpar de andarilho do mundo, com um inesgotável reportório de histórias e situações humanas, sempre cheio de narrativas desconcertantes" (FERNANDES, 1997, p. 106).
} 
O início dos jantares possui contornos semelhantes, na medida em que, conscientes do estatuto social superior do seu convidado, ambas as mulheres se preparam para o outro num movimento social vertical anotado anteriormente. No entanto, o jantar em Macau pincela-se com cores diferentes. A omnipresença da cor vermelha serve de prenúncio ao erotismo e ao amor. ${ }^{18} \mathrm{O}$ quadro sensorial é descrito mesclando sentidos visuais e olfativos. Com efeito, o leitor perceberá que a aguadeira guardara e secara as duas rosas encarnadas ofertadas, anteriormente, por Adozindo e que um chá rubro dissipa o seu odor pela casa. Por fim, as repetidas referências à boca entreaberta da chinesa e a presença de um pote fumegante de barro, no qual é trazido o manjar, completam a sensual tela. Se o leitor conhecer a obra de Senna Fernandes, poderá cruzar a referência rubra do chá com um conto do autor: "Chá com essência de cereja" presente na coletânea Nam Van. Contos de Macau. No conto destacado, a personagem de Maurício usufrui de um banho de chá - concretizado por uma chinesa - que, para além de lograr terminar com as suas enxaquecas, deixam o homem mais predisposto para os prazeres da carne: "Pois experimentem. Era um chá perfumado, quentinho... uma delícia! Perguntei-lhe que chá era aquele. Ela, a sorrir, respondeu-me que era chá vulgar... Não acredito. Ficava limpinho, bem cheiroso e depois tudo em mim era ardência" (FERNANDES, 1997, p. $63)$.

O jantar que decorre em Timor, sobre o ponto de vista da sedução, ameaça ruir. Para além do capitão não corresponder à figura padronizada que Catarina possuía sobre um verdadeiro homem do mar, os seus modos configuravam-no como um mastro inexpressivo que, ainda para mais, ignorava aspetos da cultura nativa, mais propriamente a gastronomia: "Ele olhou intrigado para a cobertura de folha de palmeira que embrulhava o peixe (...). Pensava que tinha de comer ervas e palha" (RPNS, p. 92).

No entanto, para contrariar o "naufrágio à mesa", a figura de Catarina vai apoderandose do controlo do jantar. Para este fator, concorrem a evolução e a maturação da gata de jade notados em dois episódios distintos. $\mathrm{O}$ primeiro tem que ver com o rescaldo do primeiro casamento. Na noite de núpcias, a jovem, no lugar do amor, apenas encontra a raiva do primeiro marido. A passagem é descrita com recurso a uma enumeração de vários animais, sendo possível ler-se uma bestialização do homem:

\begin{abstract}
Depois atirou-se para cima de mim como um lobo-marinho. E, num ritmo frenético e ofegante penetrou nas minhas entranhas até dar o seu grito final, um berro, um uivo, um latido, e desfazendo- se em gotas de suor que empastavam na minha pele. Consumado o acto retirou-se para o lado. Tudo foi feito num ápice. Como quando um galo se põe em cima de uma galinha. Sem um gesto de carinho. Apenas fúria, como se tivesse de fazer aquilo para se vingar de alguém (CARDOSO, 2007, p. 35).
\end{abstract}

Obviamente, o sucedido opera transformações marcantes na, então, jovem adulta de dezoito anos. ${ }^{19} \mathrm{O}$ segundo episódio dá conta da autoimagem de Catarina. Contrariamente a

\footnotetext{
${ }^{18} \mathrm{He}$ atesta o seguinte: "Red is the favourite colour for the Chinese people, it stands for the joyous meaning and happiness" (HE, 2009, p. 160). Kommonen escreve: "Red expresses happiness. In Chinese history, we seem to have never disliked red. The Chinese red is a yellowish red from cinnabar; this gives us the feeling of happiness. Consequently, red is used in celebrations; in the bridal wedding gown, in New Year's celebrations" (KOMMONEN, 2011, p. 379).

${ }^{19}$ Para completar a visão fornecida sobre a mulher, representada literariamente em Luís Cardoso, pode ser interessante olhar o cenário na vizinha Indonésia. O romance de Pramoedya Ananta Toer intitulado This Earth of Mankind representa, entre outros tópicos, as relações entre o colonizador holandês e o colonizado indonésio. Sobre o tema em apreço, na tela de Pramoedya é dado a entender que as relações entre o homem estrangeiro e a mulher nativa possuíam contornos similares. Eram, sobretudo, relações de posse nas quais os holandeses adquiriam a sua
} 
outras figuras femininas da época, a jovem surge desafiante e descreve-se como femme fatale: "os meus cabelos de seda, o nariz empinado, os olhos rasgados, a boca suculenta, o pescoço comprido. Os meus peitos firmes, a minha cintura fina, as ancas roliças, as minhas pernas esbeltas" (RPNS, p. 101). ${ }^{20}$ É à luz da explicitação de tal consciência que se pode ler a totalidade do episódio em apreço, no qual a jovem se assume protagonista e seduz o capitão: "Não gosta de viajar, capitão? Corou como se lhe tivesse feito uma proposta indecente, talvez por causa da entoação da minha voz, ou por ter reparado na minha boca e nos meus lábios carnudos. -Não me tente, Catarina" (idem, p. 93). Mais adiante, Catarina sintetiza, explicitamente: "fiz-me de inocente. Deixei de o ser, à medida que me fui dando dos azares que isso me provocava. $\mathrm{O}$ papel de vítima impedia-me de sobreviver no meio de piratas" (RPNS, p. 97).

O jantar marca, de certa maneira, uma formalização de um perpétuo ritual de concubinato. Relembre-se que, ao longo da narrativa, Catarina servirá de mulher a três capitães de porto diferentes. Em momento ulterior da narrativa, este processo é criticado sarcasticamente por Catarina que denuncia:

Primeiro oferecia-se um gato, depois perfumes, pedia-se licença para entrar pela casa adentro. Sentava-se no sofá, aceitava um café, também uma bolacha de água e sal. Olhava-se para as paredes, para o tecto e depois, como quem não quer a coisa, faziase uma vistoria aos compartimentos, ao quarto onde se dormia, também à cama, ao colchão. Enfiava-se pelos lençóis adentro, pedia mais uma almofada, uma fronha, antes de ocupar a cama toda, a casa inteira. Depois, pedia para lhe fazer a barba, aparar a unha, deixava lá esquecido um lenço onde embrulhara umas patacas (CARDOSO, 2007, p. 134).

A referência à pataca permite regressar ao jantar macaense. Recorde-se que, tal como em Macau, a pataca era a moeda oficial em solo timorense, e tinha a sua impressão a cargo do Banco Nacional Ultramarino (BNU). ${ }^{21}$

No pequeno e típico bairro de Cheok Chai Um, o erotismo do jantar culmina na concretização do desejo: "beijou-a nas faces, nas pálpebras, no pescoço, na base da nuca, exaltado pela macieza da pele na raiz dos seus cabelos. Os botões de champaca caíram sobre a mesa, com os rastos do perfume na trança" (TF, p. 62). Também em Timor, o jantar assume contornos semelhantes após o golpe de sedução de Catarina. O capitão de porto "tirava as medidas ao meu corpo como se fosse um alfaiate. Passava as mãos pelos meus cabelos, pelo rosto, pelos olhos. Desceu até aos lábios, que espremeu até ficarem rubros, antes de deslizar pelo pescoço e finalmente lançou a âncora junto do meu peito e por lá amainou. Demorava-se nos meus seios (...) (RPNS, p. 96). Aqui, contrariamente, ao jantar macaense, o clímax da

concubina numa transação de valores concretizada com os pais da mulher comprada. A mulher passava a ser a "nyai" e deveria garantir a felicidade do seu comprador. As palavras da Nyai Ontosoroh, vendida pelo pai Sostromo, resumem a situação: "They had made me into a nyai like this. So I must become a nyai, a bought slave, a good nyai, the very best nyai. I studied everything possible that my master's wants: cleanliness, Malay, making the bed, ordering the house, cooking European food (PRAMOEDY, 1990, p. 88). A nyai descreve, ainda, o seu comprador como um portento (p. 85-87) e a noite de núpcias foi bastante traumatizante: "I don't know how long that mountain of flesh was with me. I fainted, Annelies. I didn't know any longer what was happening” (idem, p. 87).

${ }^{20}$ Tal caracterização é dada em resposta à mulher do capitão do porto após um episódio de confrontação. A mulher do porto considerava Catarina apenas uma criança. Neste trecho, é possível encontrar duas imagens opostas. A mulher do capitão de porto centra-se nos pés da chinesa e vê̂ Catarina como uma criança que, por sua vez, se define e proclama como mulher.

${ }^{21}$ Sobre este assunto, consulte-se: https://www.revistamacau.com/2013/02/20/a-historia-incomum-da-afirmacaoda-pataca/ [Acesso em: 20 fev. 2020]. 
sedução é adiado pela droga que vinha ocultada no saboko: "fechou os olhos e foi-se lentamente, sem ter concretizado os seus intentos. Deixou a mãozinha ancorada no mesmo sítio do meu corpo. Tinha esperanças de que no regresso eu lhe fosse mostrar a minha caixa de Pandora" (idem, p. 97).

Levar a sedução até às últimas consequências, sem qualquer vínculo matrimonial, traz implicações negativas e pejorativas para os jovens enamorados. Em Timor, existem vocábulos que denunciam a posição da mulher que se permite envolver de tal forma: "nona' ${ }^{22}$ ou 'bombela'. ${ }^{23}$

No caso da $T F$, mesmo que existisse um casamento abeirado à cultura portuguesa, tal não teria valor aos "olhos chineses". Na cultura chinesa, espera-se que o casamento se concretize, seguindo e cumprindo um determinado ritual. O conto Pequena Flor Vermelha de António Correia permite clarificar este tópico:

é só isso que falta: casar! Quim não fez mais perguntas, porque bastou o tom da voz dela para perceber tudo. O casamento, celebrado perante o padre e registado pelo conservador do registo civil, poderia ter valor sacro ou mérito de lei; talvez tivesse até o condão de a sossegar, se tivessem ficado em Portugal, mas... estavam na China e aqui o casamento exige outros ritos e tributos, convites vermelhinhos e cheirosos com o lai-si para os bolos, mostrar o que se tem e o que não se tem, convidando o mundo todo, exibir abastança, ir com os amigos regatear o preço da noiva, servir o chá, proporcionar uma tarde de majongue e um lautíssimo banquete, requisito essencial para dar a publicidade devida ao enlace. Que será atestado pelas assinaturas dos convivas no grande pano de cetim encarnado, porque sem um jantar de ementa chinesa, com muitos pratos e cerimónias, ostentação de ouros e joias e exibição de vestidos por parte da noiva, o casamento não é reconhecido pelos familiares e amigos. -Então é isso... é a tua festa que falta... -Não é a minha festa, é a aceitação por parte da minha gente (CORREIA, 1996, p. 56).

A inexistência de laços matrimoniais coloca a felicidade em perigo e traz desonra para os amantes. O casamento funciona como uma forma de manutenção da tradição e da honra de ambos os amantes e os pais, a bem dizer, são os guardiães destes costumes, carregando um conjunto de expectativas para os filhos.

No entendimento chinês, a mulher deve ser a própria fortuna ou favorecer a sorte, trazendo os bons ventos para os negócios. O cenário torna-se perfeito quando a mulher se faz mãe de um filho varão. Leia-se a passagem do conto A desforra dum china-rico que é representativa do afirmado: "Chegado o dia, ansiosamente esperado, nasceu um soberbo varão. ${ }^{24}$ Em casa, foi uma festa. O marido e os sogros não esconderam lágrimas, violando a

${ }^{22}$ A novela A nona do Pinto Brás de Luís Filipe Thomaz permite perceber o emparelhamento entre militares portugueses e nonas. A narrativa de Cardoso define nona da seguinte forma: "em língua malaia significa senhora. Uma forma muito peculiar de dar o dito por não dito. Embora toda a gente soubesse qual a conotação exata. Era a mulher que ficava no cais a abanar o leque à espera do seguinte (RPNS, p. 46). Teresa Cunha destaca precisamente a diferença entre géneros no saldo de conflitos: após o conflito bélico, as mulheres, que foram combatentes, as que foram violadas ou escravas sexuais, as que tiveram filhas e filhos do inimigo e as que ficaram viúvas, são dificilmente reconhecidas e inseridas na sociedade que emerge. As categorias válidas para o quadro patriarcal dominante são as de virgem, esposa, filha e mãe; estas outras condições sociais, decorrentes da guerra, fazem as mulheres encararem outros ostracismos e um acesso diminuído aos recursos por criação de novas invisibilidades (CUNHA, 2006, p. 49).

${ }^{23}$ Dama de conforto para os oficiais japoneses.

${ }^{24}$ Em contraste, ocorre o oposto quando se nasce mulher: "Foi por isso que ao bebé, fadado para um papel subalterno e para um dia mudar de família, por ser de sexo feminino, foi posto o nome de Siu Hong Fa, que o mesmo é dizer Pequena Flor Vermelha" (CORREIA, 1996, p. 49). 
natural circunspeção da raça que proibia fraquezas do género. Pou In respirou e teve o seu momento de triunfo. Garantira a sucessão da melhor forma. Coincidindo com o acontecimento, os negócios dos Cheongs prosperaram, como se os ventos favoráveis conjurassem em proteger aquele lar (FERNANDES, 1997, p. 111). ${ }^{25}$

Ora, sob este prisma, a ligação de Adozindo a A-Leng revela-se péssima. A aguadeira faz-se passear com os pés sujos e descalços, não tem família de consagrado valor social nem tem posses. Surge diametralmente oposta às pretendentes de Adozindo que lhe poderiam assegurar uma vida de fausto, de tranquilidade financeira. A este aspeto acresce uma assinalável assimetria cultural à qual não é associada qualquer felicidade. De facto, as expectativas face aos namoros entre indivíduos de diferentes culturas são bastante negativas. O conto Jenny na colectânea Amores do céu e da terra - contos de Macau é disso exemplo ao apresentar uma mulher abandonada por um "kwailou", trazendo-lhe desgraça. Quando Adozindo se decide a assumir A-Leng terá que o fazer em rutura com o pai que o remove da família e o obriga a sair de casa para recomeçar a sua vida.

Sobre o episódio de Catarina e do Capitão de porto de Díli também não existe um desfecho louvável para as duas personagens. Catarina sai com o epíteto de amante, envolvida num escândalo com a legítima mulher do mesmo, e o capitão deixará o cargo para um substituto.

\section{Considerações finais}

Conforme se apresentou, os momentos destacados, passados à mesa, não se centram na vertente gastronómica. Aliás, um breve conjunto de referências ao chá, ao caranguejo e ao saboko esgotam a ementa. Apesar do simbolismo destacado e do próprio nome e apresentação conferirem um certo exotismo à narrativa, é legítimo constatar que o manjar é um tópico subalterno.

De facto, a análise encetada vale, sobretudo, pelo revelar das sinergias entre as personagens e por deixarem antever as suas movimentações no espaço, determinados acontecimentos históricos, as atitudes, os problemas e os valores sociais, assim como as próprias expectativas da época. Relembrem-se as deslocações e as caracterizações do bairro de Cheok Chai Un, as tentativas do pai de Adozindo em o casar bem, os desajustes entre as diferentes condições sociais ou os problemas advindos do belicismo nipónico.

Os relatos dos escritores logram, também, perceber a emergência de determinados tópicos como uma determinada emancipação da mulher. Tanto Cardoso como Senna Fernandes desafiam algumas conceções e dão espaço para a emergência da mulher enquanto figura central. De facto, colocam, em primeiro plano, a figura da mulher, contrariando segundo Venâncio, "uma temática, por exemplo, recorrente nas emergentes literaturas africanas em língua portuguesa, que é o da crítica à ideologia colonial que reduzia a mulher local, "colonizadas", a objeto sexual, a simples depositária da libido do colonizador" (VENÂNCIO, 2008, p. 696). Tanto Catarina como A-Leng possuem traços distintos: recebem a pessoa pretendida, tentam forjar o seu próprio destino e vão-se assumindo progressivamente autónomas no desnovelar narrativo.

\footnotetext{
${ }^{25}$ Este tipo de expectativas é altamente influenciado pela superstição chinesa que pincela o quotidiano e as escolhas mais mundanas. Num cabaret, até as damas de companhia são escolhidas pelo fong sôi, pelo ascendente da sorte: “escolheu por ele e por mim, não pelo aspeto mas pelo fong sôi dos números 38 e 88" (CORREIA, 1996, p. 34).
} 
Assim, ambos os autores enaltecem propriedades femininas que vão muito para além da complementaridade ou da subalternidade ao homem e permitem, desta forma, construir um olhar feminino válido sobre o mundo no qual que se inserem.

Na diegese de Senna Fernandes, sobretudo, desoculta-se também uma nova relação étnica que sugere um hibridismo entre portugueses e chineses. $\mathrm{O}$ movimento social entre Adozindo e A-Leng é simbólico, bastará para isso recordar que os chineses substituíram os portugueses na administração de Macau. No entanto, apesar da alternância no poder, a felicidade é possível quando ambos são respeitadores das próprias culturas e fazem as cedências necessárias do casal, reconstruindo-se e reconfigurando-se. Em certa medida, este apontamento pode constituir uma chamada de atenção e um desafio para os leitores: que se constituam conhecedores das comunidades lusófonas e das suas idiossincrasias.

\section{Referências}

AMARO, A. O traje da mulher macaense. Da Saraça ao Dó das Nhonhonha de Macau. Macau: ICM, 1989.

BARROS, L. Templos, lendas e rituais: Macau. Macau: APIM, 2003.

BRAGA, S. Making impressions: A Portuguese family in Macau and Hong Kong, 17001945. Macau: IIM, 2015.

CABRAL, J.; LOURENÇO, N. Em terra de tufões: dinâmicas da etnicidade macaense. Macau: ICM, 1993.

CARDOSO, L. Requiem para o navegador solitário. Lisboa: Dom Quixote, 2007.

CORREIA, A. Contos de Ou-Mun. Macau: Livros do Oriente, 1996.

CUNHA, T. Vozes das mulheres de Timor-Leste. Porto: Ed. Afrontamento, 2006.

D'ALTE, P. A cosmogonia occulta timorense e o mundo literário de Luís Cardoso. Olhares que se cruzam. E-revista de Estudos interculturais do CEI-ISCAP, v. 7, n. 2, p. 1-17, 2019.

D’ALTE, P. Caleidoscópio literário: a representação romanesca em Luís Cardoso. 2014. Dissertação (Mestrado em Estudos Portugueses Multidisciplinares) - Universidade Aberta, Lisboa, 2014.

DIAS, F. Amores do céu e da terra. Contos de Macau. Macau: ICM, 2014.

DURAND, F. Timor: 1250-2005 - 750 ans de cartographie et de voyages. Toulose: Ed. Arkuiris, 2006.

FERNANDES, S. A trança feiticeira. Macau: ICM, 2015.

FERNANDES, S. Nam Van. Contos de Macau. Macau: ICM, 1997. 
FIRTH, R. Fiction and Fact in Etnography. In: TONKIN, E et al (orgs.). History and Ethnicity. London: Routledge, 1989. p. 48-52.

GERBAULT, A. Seul à travers l'Atlantique et autres récits. Paris: Grasset, 1991.

GONÇALVES, M.; RODRIGUES, M. Notas sobre a possibilidade de produção do "híbrido de Timor" no seu habitat natural. Lisboa: MEAU, 1976.

HE, G. English and Chinese cultural connotation of color words in comparison. Asian Social Science, v. 5, n. 7, p. 160-163, 2009.

KOMMONEN, K. Narratives on Chinese colour culture in business contexts. The Yin Yang Wu Xing of Chinese values. Cross cultural management, v. 18, n. 3, p. 366-383, 2011.

MERCER, K. Welcome to the jungle. In: RUTHERFORD, J. (org.). Identity: community, culture and difference. London: Lawrence and Wishart, 1990.

PRAMOEDYA, A. T. This earth of mankind. Australia: Penguin Books, 1990.

SÁ, A. Timor. Sociedade de Geografia de Lisboa. Lisboa: Semana do Ultramar, 1952.

THOMAZ, L. F. A nona do Pinto Brás - novela timorense. Baucau: Fundação Dom Manuel II, 2010.

VENÂNCIO, J. C. A literatura macaense e a obra de Henrique de Senna Fernandes. Um olhar histórico-sociológico. História das ideias. Tradição e revolução. Impactum, v. 29, p. 691$702,2008$.

Recebido em: 29 de junho de 2020 Aceito em: 13 de outubro de 2020

Publicado em dezembro de 2020 